\title{
Las contribuciones de Georg Lukács al pensamiento político pedagógico de Paulo Freire
}

Fecha de recepción: 18 de diciembre de 2019.

Fecha de aceptación: 5 de marzo de 2020.

\begin{abstract}
Resumen
El presente trabajo aborda las articulaciones posibles de establecer entre los desarrollos teóricos de Georg Lukács y el pensamiento político pedagógico de Paulo Freire, enfocando el análisis en las referencias explícitas a los aportes teóricos de Lukács presentes en su Pedagogía del Oprimido, una de las obras paradigmáticas del pedagogo brasileño. Las ideas acerca de la no determinación de la conciencia por la estructura material, de la posibilidad de que la conciencia proletaria rompa el cerco de la cosificación e invierta la lógica hegemónica de la burguesía para luchar por la transformación de las estructuras de dominación, así como el lugar que ocupan la acción, la práctica, la organización y el liderazgo revolucionario en este proceso, se presentan en este primer análisis como nociones en las que se registran capilaridades entre ambos autores, más allá de los contextos históricos y geográficos y de las tradiciones intelectuales en que se inscriben.
\end{abstract}

Palabras clave: Freire, Lukács, Pedagogía, cosificación, conciencia.

\section{The contributions of Georg Lukács to Paulo Freires's pedagogical political thinking}

\begin{abstract}
The present work addresses the possible articulations to establish between the theoretical developments of Georg Lukács and the pedagogical political thought of Paulo Freire, focusing the analysis on explicit references to the theoretical contributions of Lukács present in his Pedagogy of the Oppressed, one of the paradigmatic works of the Brazilian pedagogue. The ideas of the non-determination of consciousness by the material structure, the possibility that proletarian consciousness breaks the siege of reification and reverses the hegemonic logic of the bourgeoisie to fight for the transformation of structures of domination, as well as the place which occupies action, practice,
\end{abstract}


organization and revolutionary leadership in this process, are presented in this first analysis as notions in which capillarities between both authors are recorded, beyond the historical and geographical contexts and intellectual traditions in which sign up.

Keywords: Freire, Lukács, Pedagogy, consciousness, reification.

La esencia de la historia está en producir siempre lo nuevo. Esta novedad no puede calcularse por adelantado gracias a alguna teoría infalible: debemos reconocerla en la lucha en sus primeros gérmenes y hacerla progresar hacia la conciencia clara.

Lukács, Lenin, 2007: 64

Es preciso convencerse de que el convencimiento de los oprimidos sobre el deber de luchar por su liberación no es una donación hecha por el liderazgo revolucionario sino resultado de su concienciación (...) Fue su inserción lúcida en la realidad, en la situación histórica, la que lo condujo a la crítica de esta misma situación a su ímpetu por transformarla.

Freire, Pedagogía del Oprimido, 2010: 65

\section{Introducción}

El presente trabajo aborda las articulaciones posibles de establecer entre los desarrollos teóricos de Georg Lukács ${ }^{1}$ y el pensamiento político pedagógico de Paulo Freire, enfocando el análisis en las referencias explícitas a los aportes teóricos de Lukács presentes en su Pedagogía del Oprimido (en adelante $\mathrm{PO}$ ), una de las obras paradigmáticas del pedagogo brasileño. Se trata, en el caso de este trabajo, de una reflexión acotada al rastreo y primer abordaje de estas contribuciones, ${ }^{2}$ como parte de un programa más amplio destinado a estudiar la presencia de las categorías propias del análisis marxista en el pensamiento de Freire.

La tarea adquiere relevancia, en tanto existe una relativa coincidencia entre los estudiosos de la obra de Freire respecto a la influencia que ejercieron en esta diversos intelectuales marxistas, particularmente los de matriz hegeliana, que se articuló con la perspectiva construida en la etapa inicial de su producción intelectual, en las décadas de 1950 y 1960. La mayor o menor consistencia de estas relaciones ha sido objeto de discusión y resulta particularmente controversial, según el punto de vista que se adopte. Sin duda, la obra de Freire, como toda elaboración teórico-práctica, constituye una producción social históricamente situada. Como tal, reconoce la impronta de los debates latinoamericanos de las Ciencias Sociales de la época, en los que se involucra desde la particular tradición intelectual en la que el brasileño se referencia, principalmente vinculada al pensamiento católico renovador.

Con este propósito, en una primera parte, el trabajo presentará de manera muy sintética las visiones que diversos autores sostienen sobre las relaciones que es posible establecer entre el pensamiento marxista y los desarrollos freireanos. Luego se realizará una

1 Georg Lukács (1885-1971, Budapest, Hungría), se formó en las universidades de Budapest, Berlín y Heidelberg. Se afilió al PC húngaro en 1918 y participó en 1919 en el gobierno como Comisario del pueblo de Cultura y Educación. Fue uno de los promotores de la Revolución húngara de 1956, en la que se desempeñó como Ministro de Cultura. Fue perseguido y deportado por el estalinismo.

2 En el marco del proyecto de investigación “Los procesos de escolarización de los jóvenes en los Centros Educativos de Nivel Secundario del Conurbano Bonaerense. Democratización de la educación, discriminación y reconocimiento”, desarrollado en la Universidad Pedagógica Nacional-Programación científica 2018-2020. 
introducción al pensamiento de Lukács, a través de algunas nociones teóricas presentes en su obra Historia y conciencia de clase, vinculadas con su idea de la "cosificación" como un fenómeno definitorio de la sociedad moderna, conceptos que resultan centrales para abordar el análisis de sus aportaciones intelectuales al pensamiento freireano. Finalmente, se profundizará en el desarrollo de las categorías lukácsianas cuya influencia reconoce explícitamente el pedagogo en su obra Pedagogía del Oprimido.

\section{Algunas perspectivas sobre la inscripción intelectual de los desarrollos freireanos y sus diálogos con el marxismo}

Diversos trabajos que se proponen analizar la obra de Paulo Freire acuerdan respecto de las particularidades que presenta su "matriz de pensamiento y un modo de producción intelectual" que elude las articulaciones de una teoría acabada (Rodríguez, 2008: 10). En esta perspectiva se ubican los señalamientos que aluden a su producción en términos de la "visión" de "un pensador ecléctico" (Coben, 2001: 87-86), una “obra práctico-teórica" (Scocuglia, 1999: 33), con un marcado "estilo literario" (Gerhardt, 1999).

Para unos, un pensamiento complejo, una teoría y una praxis educativa avanzada. Para otros, un pensamiento incompleto, falto de rigor científico, necesitado de elaboración teórica, que continuó repitiéndose a sí mismo y perdió vigencia. (Torres, 2001)

Coincidimos con Rodríguez cuando plantea que

(...) el pensamiento nacional desarrollista del Instituto Superior de Estudios Brasileños y el pensamiento católico renovador son las principales referencias de base sobre las que organiza la matriz de su pensamiento, tanto en lo que se refiere a los postulados fundantes como en el tipo de intelectual con fuerte vocación de intervención en la realidad de Brasil. (Rodríguez, 2008: 72)

Desde la perspectiva de Taylor, uno de sus principales críticos desde el marxismo, en Freire, "el lenguaje de la fe cristiana es más que mero ropaje de apariencia: realmente constituye el esqueleto o el apuntalamiento de su análisis filosófico y social" (Taylor, 1993: 56, en Coben, 2001: 106).

Es sobre este trasfondo que han resultado particularmente controversiales las diversas aportaciones provenientes del marxismo que Freire incorpora a lo largo de su recorrido intelectual y que comienzan a hacerse visibles en sus escritos en la predominancia de citas bibliográficas de autores marxistas que incluye en la Pedagogía del Oprimido. En efecto, progresivamente, Freire explica el papel central de las ideologías en la producción y reproducción de las estructuras de clase, tomando conceptos de las perspectivas neomarxistas, nociones que replantean el economicismo propio de las versiones del marxismo vulgar. $\mathrm{Y}$, al respecto, las críticas se dirigen a la consistencia interna de su pensamiento, toda vez que no se observa que la consideración de "Marx, Engels y Gramsci, más Sartre, Lukács, Amílcar Cabral, entre otros, determinaran una ruptura con las posiciones liberalizantes, nacionalistas, desarrollistas y, ciertamente, populistas, de los años '50 y '60."3 (Scocuglia, 1999: 33).

3 En esta polémica se inscribe la impugnación intelectual que la pedagoga brasileña marxista Vanilda Paiva efectúa de la corriente latinoamericana de la Educación Popular, cuando tilda de "populismo pedagógico" al pensamiento de Freire, a partir de postular que "sus orígenes ideológicos deben buscarse en el movimiento de renovación católica de finales de los años cincuenta y principio de los sesenta, en el cual ya se ha identificado la presencia de elementos ideológicos análogos a aquellos encontrados en el populismo ruso del siglo XIX" (Paiva, 1982: 3). Situada en la perspectiva del "nacionalismo popular", Adriana Puiggrós critica el señalamiento de Paiva desde su hipótesis de que la "moderna versión del racionalismo pedagógico de izquierda critica la búsqueda de articulaciones entre teoría e ideología que justificarían el vínculo educativo 
En este marco, en un primer abordaje de la cuestión, es posible delimitar la influencia del pensamiento de Lukács en la producción freireana de Pedagogía del Oprimido, con referencia a los problemas teórico-prácticos intervinculados de la "concientización" de los sectores sociales subalternos y, específicamente, a la discusión sobre el papel que le corresponde al liderazgo revolucionario en este proceso. A continuación, el análisis se basará en la presentación del tratamiento que Lukács hace de estos problemas en las obras Historia y conciencia de clase y Lenin, ${ }^{4}$ ambas citadas por Freire en PO.

\section{Una aproximación al pensamiento de Georg Lukács ${ }^{5}$}

Lo que configura como marxista al pensamiento de Lukács es su matriz dialéctica, histórica, de abordaje de los procesos sociales, un análisis que solo puede ser sostenido desde el punto de vista de la totalidad. El intelectual y militante húngaro retoma de Hegel la propuesta de formular una Filosofía de la Historia, concebida como una teoría integral del desarrollo social y, para el despliegue de este programa, adopta el materialismo histórico introducido por Marx, en su calidad de abordaje que permite construir esa teoría con valor científico. A partir de aquí, afirma una perspectiva sistemática, crítica, para comprender la Historia y, específicamente, el papel que cumplen la lógica de la producción y la consecuente alienación en la sociedad burguesa, tomada en su valor de negatividad.

Esta perspectiva teórica construye otro sentido para la idea de "crítica", un sentido que, fundado en la noción de una no determinación de la superestructura ideológica por parte de la estructura material económica, habilita la posibilidad de que —-desde la representación, desde la lógica interpretativa - el capitalismo sea cuestionado adoptando la óptica de la clase proletaria. En tanto los intereses del proletariado son concebidos como objetivamente universales, la apertura de la crítica resulta sustantiva para el desarrollo histórico.

El materialismo histórico tiene una función decisiva en esa lucha por la conciencia. El proletariado y la burguesía son clases coordinadas en lo ideológico igual que en lo económico. (...) Ideológicamente, esto significa que la misma lenta comprensión de la esencia de la sociedad, en la que se refleja la lenta agonía burguesa, redunda para el proletariado en un constante aumento de fuerzas. La verdad es para el proletariado un arma victoriosa. (Lukács, 1984, II: 151-152)

Cabe señalar que esta cuestión de la "correspondencia" entre las relaciones de producción y la superestructura, en su carácter de conexión no necesaria, y el consiguiente lugar en el que coloca la dimensión cultural en los procesos de transformación social, constituye un elemento constitutivo del pensamiento de Paulo Freire. Así lo plantea este autor a lo largo de sus obras y, particularmente, en PO, cuando abre la posibilidad de que

\footnotetext{
como un vínculo de intercambio entre los intelectuales y las masas, es decir un vínculo político-pedagógico en el sentido gramsciano. (...) Así, la Educación Popular, para no ser tachada de irracionalista, moralista, utópica y falsamente revolucionaria, debe ser 'científica', es decir, adoptar los postulados del marxismo leninismo clásico en forma taxonómica, rechazar aquello que provenga del 'folklore' popular y difundir la doctrina” (Puiggrós, 1986: 28-29).

4 Específicamente en los capítulos "La cosificación y la conciencia del proletariado" y "Conciencia de clase" de su obra Historia y consciencia de clase, y "El partido dirigente del proletariado" del texto Lenin, fechado por su autor en marzo de 1920. 5 Una periodización del pensamiento de Georg Lukács permite delimitar una primera etapa intelectual en la cual centra sus análisis en torno al arte y su sentido (1911-1916) para, en un segundo momento (1917-1923), reflexionar sobre los problemas que la Revolución rusa plantea en los planos de la teoría y la práctica. Se trata de una reflexión signada por una mayor impronta marxista presente en esta segunda etapa y que se expresa en la obra central del período: Historia y conciencia de clase (1923). Finalmente, en la última etapa, en la cual es impugnado por la Tercera Internacional, conjuntamente con Gramsci y otros intelectuales, Lukács retoma la crítica del arte, con un abordaje marcadamente materialista.
} 


\begin{abstract}
(...) los oprimidos, en su lucha por la liberación, no conciban la realidad concreta de la opresión como una especie de "mundo cerrado" (...) sino como una situación que solo los limita y la cual ellos pueden transformar (...) la Pedagogía del Oprimido, como pedagogía humanista y liberadora (...) será siempre la acción profunda a través de la cual se enfrentará, culturalmente, la cultura de la dominación. (Freire, 2010: 42 y 50)
\end{abstract}

Por su parte, Lukács, en Historia y conciencia de clase, parte de abordar el proceso revolucionario soviético, y postula que en tanto es el proletariado, como sujeto colectivo, el que protagoniza una ruptura fuerte y práctica, es posible desde ese proceso pensar el mundo capitalista ya no desde una perspectiva fatalista sino desde la ruptura que conlleva la revolución como salida práctica. Más allá de ser un fenómeno de época, la Revolución rusa constituye, desde su perspectiva, un evento universal cuya trascendencia resulta decisiva en la historia. Y, a diferencia de lo acaecido en la Revolución burguesa, en este caso es una clase universal, en función de que sus intereses coinciden con los de toda la humanidad - el proletariado- la que se hace cargo del desarrollo histórico. Se trata de un sujeto de carácter superior, cualidad que se atribuye a su cultura, el que pone en marcha la conciencia en otro territorio, estructural, el de la política, el de la práctica. De esta forma, la perspectiva lukácsiana postula el dominio de la práctica sobre la teoría, una relación en la cual la acción revolucionaria del proletariado no se limita a crear una nueva teoría en los marcos de la sociedad burguesa, sino que transforma radicalmente la lógica social existente en el proceso de creación de una sociedad nueva.

De este modo, inscripto en la óptica kantiana de la superioridad espistémica del punto de vista de la totalidad, y en la perspectiva anticapitalista de la tradición intelectual alemana que opone "civilización" a "cultura", Lukács emprende una crítica ideológica que habilite a pensar el todo, a avanzar más allá de la racionalidad burguesa y, particularmente, a considerar una dimensión crucial omitida en esta: la de la práctica.

Freire, por su parte, parece coincidir con este abordaje analítico: la pedagogía del oprimido se propone la problematización del mundo de la dominación que ha sido naturalizado por parte de los sectores subalternos, planteándose como un proceso producido por y productor de una respuesta en el nivel de la práctica:

Estamos convencidos de que la reflexión, si es verdadera reflexión, conduce a la práctica. Por otro lado, si el momento es ya de la acción, esta se hará praxis auténtica si el saber que de ella resulta se hace objeto de reflexión crítica. (Freire, 2010: 63)

(...) porque [los oprimidos] captan el desafío como un problema en sus conexiones con otros, en un plano de totalidad y no como algo petrificado, la comprensión resultante tiende a tornarse crecientemente crítica y, por esto, cada vez más desalienada. (Freire, 2010: 87)

La noción lukácsiana de "cosificación" es pensada en un escenario histórico en el que el modelo de producción taylorista, que se encuentra consolidado en Occidente desde 1915, coloca al proletariado en la condición de ser un elemento más de la máquina, al servicio de la producción capitalista. Desde esta perspectiva, postula que la impregnación generalizada de la estructura de la mercancía en la sociedad burguesa se erige en la problemática central y sustantiva del capitalismo moderno. Desde esta concepción teórica, la cosificación, como una forma de la alienación, radica en la

(...) esencia de la estructura de la mercancía (...), se basa en que una relación entre personas cobra el carácter de una sociedad y, de este modo, de una "objetividad fantasmal" que con sus leyes propias rígidas, aparentemente conclusas del todo y racionales, esconde toda huella de su naturaleza esencial: el ser una relación entre 
En el marco de un abordaje de la totalidad, Lukács se interesa por las implicancias ideológicas de la alienación, es decir por la "correspondencia", indeterminada, que esta asume en las formas de subjetividad propias de la sociedad burguesa. Particularmente, como ya se afirmó más arriba, el autor recalca el imperativo de superar los límites de la ideología burguesa, de no restringir la reflexión al ámbito de la teoría y, al avanzar más allá de Kant, poder pensar la práctica, la política ordenada a liberarse de esa 'segunda naturaleza’ producida" (Lukács, 1984, I: 11).

Así, postula que la predominancia del trabajo mercantil y su estructura como forma generalizada y objetivada de relación entre los hombres propia del capitalismo burgués indica la presencia de un tipo social cualitativamente diferente del que caracteriza a las sociedades en las cuales estos intercambios adoptan un carácter intermitente. En sus términos:

(...) la mercancía no es conceptuable en su naturaleza esencial sin falsear más que como categoría universal de todo el ser social. Solo en este contexto cobra la cosificación producida por la relación mercantil una importancia decisiva, tanto para el desarrollo objetivo de la sociedad como para la actitud de los hombres respecto de ella, para la sumisión de su conciencia a las formas en las que se expresa esa cosificación, para los intentos de entender el proceso o de rebelarse contra sus mortales efectos y liberarse de la servidumbre. (Lukács, 1984, I: 11)

Para pensar el mundo del trabajo, Lukács retoma la idea de reificación que Marx introduce en el primer capítulo de El Capital: la de un extrañamiento del trabajador respecto de su propio trabajo y de sus relaciones sociales en el conjunto de los procesos de producción. Estos se le presentan bajo la apariencia de una "cosa" autónoma e inmanejable, de un objeto ajeno a su propia humanidad y por el cual es dominado, obedeciendo a leyes naturalizadas. Desde esta concepción, la cosificación adopta una doble dimensión: una forma objetiva en la constitución del mercado y las leyes que lo gobiernan, aparentemente universales; y una forma subjetiva en la transformación de la actividad del trabajador y sus relaciones en una "cosa" que se comercializa en función de la lógica mercantil.

Lukács aplica el concepto marxista de "alienación" al proceso de racionalización de la sociedad propio de la división capitalista del trabajo, ya postulado por Weber. La cosificación, desde su perspectiva, es resultado de la operación de abstracción de la que resulta la mercancía: las diferencias cualitativas y humanas de los productos y de los trabajadores individuales son formalizadas en un plano de igualdad, condición para su intercambiabilidad obedeciendo al cálculo mercantil. En este marco, la alienación se produce por dos vías: a través de la descomposición y mecanización repetitiva del proceso de trabajo y con el avance de la especialización, que fragmenta la fabricación de un producto completo y profundiza la desconexión de las actividades que referían unas a otras en el modo artesanal. Paradójicamente, postula, que bajo la apariencia de una atomización, el capitalismo tiende a someter a todas las áreas de la sociedad, de manera unitaria, a su propia lógica económica del cálculo privado.

En este punto, Lukács propone una interpretación humanista que acentúa la conexión Hegel-Marx. Advierte la deshumanización resultante de la racionalización, mecanización y especialización científicas del moderno mundo del trabajo y aborda el análisis de sus implicancias subjetivas y comunitarias, en tanto procesos que conllevan 
(...) el desgarramiento de su sujeto (...) la actividad del trabajador va perdiendo cada vez más intensamente su carácter mismo de actividad, para convertirse paulatinamente en una actitud contemplativa (...) los sujetos tienen que descomponerse racionalmente de un modo análogo. (...) porque su trabajo parcial mecanizado, la objetivación de su fuerza de trabajo, se convierte en realidad cotidiana permanente e insuperable, frente a su personalidad total, consumando el proceso iniciado con la venta de esa fuerza de trabajo. (Lukács, 1984, I: 14).

La dominación de la forma mercancía en todos los órdenes de la sociedad burguesa, en otros términos, para Lukács, la universalización del destino del trabajador, se potencia con la impregnación de esta estructura cosificada en las conciencias de los hombres "cada vez más profundamente, fatal y constitutivamente" (Lukács, 1984, I: 19). El carácter encubridor de la ideología se asocia a la inserción contemplativa, pasiva, de los sujetos en la sociedad capitalista, naturalizada como un sistema autorreferente que se gobierna según leyes objetivas como una totalidad ilusoria. De esta forma, "la fuente del beneficio es ya irreconocible y el resultado del proceso de producción capitalista - separado del proceso mismo- cobra existencia independiente" (Lukács, 1984, I: 20).

Desde la óptica de Lukács, fuera del universo fabril, la creciente burocratización y su consiguiente ética de la responsabilidad constituyen la expresión, en el terreno de las facultades intelectuales más elevadas, del mismo fenómeno de la cosificación que se verifica en todas las esferas de la sociedad burguesa. En el nivel de la producción científica, la ciencia que produce este tipo de formación social impregnada por la estructura de la mercancía, reproduce los parámetros de especialización que le impiden dar cuenta de la totalidad de la dinámica social, por lo tanto, también del recorte de realidad que intentan interpretar en cada caso. Desde esta perspectiva, la ciencia burguesa, sujeta a los propios intereses de clase, presenta un límite producido por su propia racionalidad que obtura la crítica ideológica y la restringe a una perspectiva ahistórica. No puede captar el carácter de producción social relativa a la totalidad concreta de su objeto de estudio, de sus propios marcos metodológicos y del conocimiento que genera. Inevitablemente, el conocimiento burgués concibe y naturaliza el mundo cosificado como única posibilidad de inteligibilidad: "en el terreno de la sociedad burguesa es imposible una alteración radical del punto de vista" (Lukács, 1984, I: 39).

En un nivel de análisis preliminar, estos planteos remiten a algunos señalamientos que formula Freire respecto de los límites propios de la teoría y la práctica pedagógica hegemónicas, que él denomina "educación bancaria". Con el fin de evitar la problematización de la estructura opresora, de modo de obturar una acción transformadora de la realidad, esta pedagogía "domesticadora"

(...) insiste en mantener ocultas ciertas razones que explican la manera como están siendo los hombres en el mundo y, para esto, mitifican, la realidad (...) como algo detenido, estático, dividido y bien configurado (...) retazos de la realidad, desvinculados de la totalidad en que se engendran y adquieren sentido. (Freire, 2010: 89 y 71)

\section{Las referencias explícitas de Freire al pensamiento de Lukács}

Como ya se ha señalado, en PO Paulo Freire alude explícitamente a los planteos teóricos de Georg Lukács en dos únicos pasajes. En ambos, refiere al desarrollo de la conciencia de la opresión por parte de los sectores dominados —en sus términos, la "emersión" de 
la conciencia" y su "inserción crítica" - y al rol que le cabe al liderazgo revolucionario en este proceso de "concientización" y su correspondiente pedagogía.

\section{Algunas notas sobre la presencia del enfoque lukácsiano en el abordaje frei- reano de la conciencia de los oprimidos}

En el capítulo IV de PO, en el apartado referido a la "invasión cultural", el pedagogo alude, en la nota al pie, a la diferencia que es posible establecer entre las "necesidades de clase" y la "conciencia de clase", y explicita que "A propósito de 'conciencia de clase" debe consultarse la obra Historia y Conciencia de clase de Lukács (Freire, 2010: 200). ${ }^{6}$ La línea argumental de Freire, que culmina con esta nota donde reenvía a Lukács, parte de la afirmación de que el liderazgo revolucionario "en forma general" es fruto de una renuncia a su clase por parte de "hombres que de una forma u otra participaban de los estratos de los dominadores", renuncia producida "en un acto de verdadera solidaridad", "de amor y de real compromiso", sea o no como resultado de "un análisis científico" (en alusión evidente a la adhesión del dirigente al análisis marxista) (Freire, 2010: 199). Con este punto de partida, postula Freire, se crearían las condiciones para una conexión comunicativa entre el líder y las masas.

Las masas populares necesitan descubrirse en el liderazgo emergente y este en las masas. En el momento en que el liderazgo emerge como tal, necesariamente se constituye como contradicción de las elites dominadoras.

Las masas oprimidas, que son también, contradicción objetiva de estas elites, “comunican" esta contradicción al liderazgo emergente.

Esto no significa que las masas hayan alcanzado un grado tal de percepción de su opresión, de la cual puede resultar el reconocerse críticamente en antagonismo con aquellas.

Pueden estar en una postura de "adherencia" al opresor (...) También es posible que, en función de ciertas condiciones históricas objetivas, hayan alcanzado, si no una visualización clara de su opresión, una casi "claridad” de esta. (...) una vez alcanzada la claridad o la "casi claridad" de la opresión, factor que las lleva a localizar al opresor fuera de ellas, aceptan la lucha para superar la contradicción en que están. En este momento superan la distancia mediadora entre las "necesidades" de clase objetivas y la "conciencia de clase". (Freire, 2010: 199-200)

En un sentido, Freire alude a la formulación de Lukács según la cual la práctica de la clase proletaria se dirige objetivamente a la transformación revolucionaria de la estructura de dominación como única alternativa de satisfacción de sus necesidades, las cuales no pueden ser resueltas en ninguna instancia parcial (Bavasso, 2008: 12).

Para abordar estas afirmaciones de Freire, se retoma el desarrollo realizado por Lukács, en el capítulo "Conciencia de clase" de Historia y conciencia de clase. Allí, el autor se interroga acerca de la significación teórica de esa categoría y sobre las implicancias que acarrea esta conceptualización en el terreno práctico de la lucha de clases, en sus articulaciones, gradaciones y en el caso específico de la clase proletaria. Porque si la forma mercancía, que rige la sociedad burguesa, "imprime su estructura a toda la conciencia del hombre" (Lukács, 1984: 29), un aspecto crucial entonces deriva de la pregunta por la posibilidad de que el proletariado se asuma activamente como sujeto de la transformación social, en su vinculación con la totalidad. 
Lukács parte de puntualizar, retomando a Engels, la diferencia de orden que existe entre los pensamientos, sentimientos, valoraciones de los sujetos individuales y la conciencia de clase, y afirma que "la esencia del marxismo científico consiste en el conocimiento de la independencia de las fuerzas realmente motoras de la historia respecto de la conciencia (psicológica) que tengan de ellas los hombres" (Lukács, 1984, II: 126).

Así, pues, la conciencia de clase es - considerada abstracta y formalmente - al mismo tiempo una inconciencia, clasísticamente determinada, de la propia situación económica, histórica y social. Esta situación se da como una determinada relación estructural, como una determinada relación formal, que parece dominar todos los objetos de la vida. Por tanto, la "falsedad", la "apariencia”, contenida en esa situación, no es nada arbitraria, sino, precisamente, expresión mental de la estructura económica objetiva. (Lukács, 1984, II: 132)

Desde esta óptica, conceptualiza la conciencia de clase merced al establecimiento de una correspondencia entre las relaciones de producción y su manifestación en el plano de la superestructura:

(...) la conciencia de clase es la reacción racionalmente adecuada que se atribuye de este modo a una determinada situación típica en el proceso de producción (...) que se diferencia de las ideas de los hombres acerca de su posición en la vida, ideas empíricofactuales, describibles y explicables psicológicamente. (Lukács, 1984, II: 131)

Complementariamente, el autor señala que cuando se supera la percepción deformada de la realidad que se desprende de la lógica de la cosificación, y se avanza hacia una consideración de la totalidad concreta

(...) se descubren las ideas, los sentimientos, etc. que tendrían los hombres en una determinada situación vital si fueran capaces de captar completamente esa situación y los intereses resultantes de ella, tanto respecto de la acción inmediata como respecto de la estructura de la entera sociedad, coherente con esos intereses (...) (adecuados) a su situación objetiva. (Lukács, 1984, II: 131)

En ese marco, Lukács se interroga por las implicancias prácticas, para el desarrollo social, de la articulación entre la estructura material económica, la conciencia de clase "atribuida" y las ideas de los hombres en el plano psicológico-subjetivo.

Parte de señalar que, a diferencia de las sociedades precapitalistas, a cuyos estratos sociales les resulta inalcanzable la posibilidad de acceder a la comprensión de la totalidad concreta, la sociedad burguesa realiza en sí misma "el interés económico de clase como motor de la historia" (Lukács, 1984, II: 140) y, de este modo, "la conciencia de clase entra en el estadio de conciencia refleja posible" (Lukács, 1984, II: 141). Desde esta comprensión, siendo la burguesía y el proletariado "las únicas clases puras" de esta estructura social, ambas se encuentran articuladas tanto en el plano económico como en sus implicancias ideológicas.

Con este presupuesto, el autor aborda la delimitación de diferencias cualitativas entre la conciencia de clase de la burguesía y la del proletariado. Desde su perspectiva teórica, la burguesía refleja una conciencia "falsa", objetivamente determinada por su posición de clase en las relaciones de producción del mundo burgués, que en condiciones de emergencia de la confrontación social con el proletariado tiende a devenir en "falsedad" moral en el plano subjetivo. Esta clase afronta contradicciones dialécticas estructurales que debilitan su posición en el esquema de poder social y la colocan a la defensiva, antagonismos que reflejan en su conciencia de clase las contradicciones insolubles de 
la estructura económica capitalista como totalidad concreta, y por las cuales pierde “inapelablemente su capacidad de dirección (Lukács, 1984, II: 151).

La otra clase pura, el proletariado, constituye, para Lukács, la "configuración histórica consciente y activa" (1984, II: 148) que ilumina el momento práctico, positivo, de la lucha de clases necesaria a la estructura objetiva. Para el proletariado, el progresivo conocimiento de la totalidad concreta, en el plano de la dimensión cultural de la lucha política, en cuyo proceso el materialismo dialéctico tiene un rol decisivo, constituye un elemento estratégico en el terreno práctico de la lucha de clases. En su caso, en condiciones objetivas de crisis estructural del capitalismo, esta clase puede (y "debe", señala Lukács) tomar conciencia de la estructura material articulada con una coincidencia objetiva entre la teoría y la práctica (proceso negado a la burguesía). Se trata del acceso a la "conciencia atribuida", que empuja el desarrollo histórico hacia una nueva estructura social sin clases, en respuesta a las necesidades objetivas de todos los hombres. Para esta clase, "la 'ideología’ se convierte en 'la finalidad y el arma mismas” (Lukács, 1984, II: 154).

Como es natural, el proletariado tiene que partir de la situación inmediata. Pero se distingue de las demás clases por el hecho de que no se detiene ante los acaecimientos singulares de la historia, ni tampoco se deja simplemente arrastrar por ellos, sino que constituye él mismo la esencia de las fuerzas motoras y actúa centralmente sobre el centro mismo del proceso de desarrollo social. (Lukács, 1984, II: 152)

De este modo, distanciándose del materialismo vulgar y del idealismo utopista, Lukács sostiene que para esta clase sí es posible superar la cosificación de la conciencia. En este proceso, las condiciones objetivas crean una posibilidad para el proletariado, una "tendencialidad objetiva", que de ningún modo lo exime del acto consciente, activo, que lo conduzca más allá de las necesidades empíricas inmediatas. Se trata, para esta clase social, de rebasar la mera crítica de la cosificación como momento de negatividad para, por medio de la articulación de las dimensiones económica y política de la dominación, orientar su práctica hacia la finalidad de una transformación social que lo libere de una forma definitiva, y con ella a toda la humanidad, de la cosificación estructural a que la someten las relaciones de producción capitalista. Un proceso en el cual el proletariado libra una lucha simultánea contra la burguesía como clase enemiga y "consigo mismo, con los efectos destructores y humillantes del sistema capitalista en su conciencia de clase" (Lukács, 1984, II: 166).

En la concepción de Lukács, de esta forma, la conciencia de clase es "el sentido hecho consciente, de la situación histórica de la clase", tal como el autor lo interpreta en los planteos del joven Marx en el Epistolario de 1843 (Lukács, 1984, II:1 58) y en la polémica con Hegel en la Sagrada Familia:

La conciencia no se encuentra fuera del desarrollo histórico. No tiene que esperar a que el filósofo la introduzca en el mundo (...) "Solo mostramos al mundo aquello por lo cual propiamente lucha, y la conciencia es cosa que no tiene más remedio que apropiarse aunque no quiera". Por eso, se trata solo de "explicarle sus propias acciones". (Lukács, 1984, II: 162)

Es en un sentido convergente que Freire parece conceptualizar la diferencia entre "necesidades de clase" y "conciencia de clase". La dominación en el plano cultural, la naturalización del orden de la dominación es para el pedagogo brasileño "uno de los problemas más graves que se oponen a la liberación. Es que la realidad opresora, al constituirse casi como un mecanismo de absorción de los que en ella se encuentran, funciona como una fuerza de inmersión de las conciencias" (Freire, 2010: 45). 
Para los dominados, hacer de la opresión y sus causas un objeto de reflexión, y, más aún, someter a crítica la propia conciencia, la visión que van construyendo sobre la estructura social de deshumanización se plantea como el nudo sustantivo de la pedagogía del oprimido.

Pensarse a sí mismos y al mundo, sin dicotomizar este pensar de la acción.

La educación problematizadora se hace, así, un esfuerzo permanente a través del cual los hombres van percibiendo, críticamente, cómo están siendo en el mundo, en el que y con el que están. $\mathrm{Si}$, de hecho, no es posible entenderlos fuera de sus relaciones dialécticas, si estas existen, independientemente de si las perciben o no, o independientemente de cómo las perciben, es verdadero también que su forma de actuar (...) es, en gran parte, en función de la forma como se perciben en el mundo. (Freire, 2010: 89)

Sin embargo, la concepción de "conciencia de clase" que sostiene Freire constituye una de las cuestiones relevantes de abordar en un análisis más completo de su obra. Resulta particularmente controversial, y sobre ella los estudiosos de origen marxista han centrado gran parte de sus críticas. En efecto, algunos analistas postulan la existencia de una evolución: la noción de conciencia de inspiración existencialista cristiana que Freire toma de Vieira Pinto y otros ideólogos del ISEB (la idea de la progresión de la concientización a través de niveles de conciencia que evolucionan hasta alcanzar la conciencia crítica), que caracterizaría la primera etapa de su pensamiento, posteriormente "se disloca, gradualmente, hacia la 'conciencia de clase' lukácsiana" (Scocuglia, 1999: 35). Otros abordajes, en cambio, señalan que en su obra la noción resulta "evasiva", principalmente debido a que "el concepto de clase de Freire se muestra abstracto y mecánico" (Coben, 2001: 113-114). Sus críticos le atribuyen un despojo del carácter material del concepto de "clase", para asociarla al resultado de una elección moral, lo cual estaría privando a su pensamiento de una herramienta esencial del análisis genuinamente marxista. Desde esta perspectiva Paiva, referenciada en el partido comunista brasileño, niega toda influencia de Lúkács en la pedagogía freireana y afirma que, partiendo de esta concepción de "conciencia"

No sería posible echar mano de un criterio objetivo de verdad o falsedad, porque la "verdad de la masa" sería auténtica o inauténtica, no correcta o errada. Simplemente, cuando fuese auténtica, reflejaría la realidad -ya que él consideraba que la base económica condicionaría la conciencia- expresando su aprehensión del mundo a partir de su situación vital, referida fundamentalmente al mundo del trabajo. Este materialismo mecanicista, en el que algunos quisieran ver la influencia de Lukács, aparece, en verdad, como una radicalización del vitalismo: lo vivido se refleja en la conciencia, la experiencia empírica y no la abstracción es fuente de lo auténtico (de la "verdad"), el método para llegar a la comprensión de lo real es inductivo, parte de la vida y no del pensamiento (hipotético-deductivo). (Paiva, 1982: 12)

La ausencia de una definición más clara respecto del papel que juega la lucha de clases como motor del desarrollo histórico, se encuentra en la base de estas ambigüedades. El propio Freire, en su obra Pedagogía de la esperanza pasa revista a las críticas recibida desde el marxismo sobre PO en la década de 1970, entre ellas, a su noción de que "la adherencia a la realidad en que se encuentran las grandes masas campesinas de América Latina exige que la conciencia de clase oprimida pase, si no antes, por lo menos concomitantemente, por la conciencia del hombre oprimido" (Freire, 2009: 115). Y cierra su argumentación afirmando que "la lucha de clases no es el motor de la historia, es ciertamente uno de ellos” (Freire, 2009: 116). 
Es preciso contextualizar esta afirmación de Freire en el marco de su producción. Al respecto, coincidimos con Mayo cuando afirma que en el pensamiento freireano "la discusión sobre la opresión y la liberación se realiza dentro del marco histórico de la colonización brasileña y latinoamericana (predicada en la expropiación y la exterminación humana racista)" (Mayo, 2010: 3). En este contexto, la cuestión de la lucha de clases debe interpretarse en el marco de la concepción de la revolución en términos de un movimiento anticolonialista de liberación nacional, perspectiva dominante en la izquierda de la región en esas décadas. Una visión que rechaza la idea marxista del proletariado industrial como clase superior, ${ }^{7}$ considerada esta como una noción que no reconocería el potencial revolucionario de los sectores mayoritarios de las sociedades latinoamericanas (el campesinado mestizo e indígena y los trabajadores informales de los centros urbanos).

\section{El problema del papel pedagógico del liderazgo revolucionario}

La otra mención explícita del pensamiento lukácsiano se registra en el capítulo primero de PO. Allí, el pedagogo brasileño transcribe textos del capítulo III "El partido dirigente del proletariado" de la obra de Lukács, Lenin, ${ }^{8}$ y señala:

Es interesante observar la advertencia que hace Lukács al partido revolucionario sobre que “(...) debe, para emplear las palabras de Marx, explicar a las masas su propia acción, no solo con el fin de asegurar la continuidad de las experiencias revolucionarias del proletariado, sino también de activar conscientemente el desarrollo posterior de estas experiencias".

Al afirmar esta necesidad, Lukács indudablemente plantea la cuestión de la "inserción crítica" a que nos referíamos. "Explicar a las masas su propia acción” es aclarar e iluminar la acción, por un lado, en lo que se refiere a su relación con los datos objetivos que la provocan y, por otro, en lo que dice respecto a las finalidades de la propia acción.

Cuanto más descubren, las masas populares, la realidad objetiva y desafiadora sobre la cual debe incidir su acción transformadora, tanto más se "insertan” en ella críticamente.

De este modo, estarán activando “conscientemente el desarrollo” de sus experiencias.

En un pensar dialéctico, acción y mundo, mundo y acción se encuentran en una íntima relación de solidaridad. Aún más, la acción solo es humana cuando, más que un mero hacer, es quehacer, vale decir, cuando no se dicotomiza de la reflexión. Esta última, necesaria a la acción, está implícita en la exigencia que plantea Lukács sobre la "explicación a las masas de su propia acción", como se encuentra implícita también en la finalidad que él da a esa explicación: la de "activar conscientemente el desarrollo posterior de la experiencia” (Freire, 2010: 47 y 48).

En el texto al que alude Freire, Lukács retoma el pensamiento de Lenin para señalar la relevancia estratégica de la organización de la clase proletaria en un partido comunista, que aglutine sujetos cuya conciencia de clase se encuentre desarrollada, y que se constituya, de este modo, en "la encarnación visible de la conciencia de clase del

\footnotetext{
7 Considerada esta como una cuestión polémica, Dos Santos refiere críticamente a algunos desarrollos de la Teoría de la Dependencia, particularmente a la postura de Gunther Frank, a quien le atribuye un "desprecio por las relaciones de producción asalariadas, como fundamento más importante del capitalismo industrial, única forma de producción capitalista en la cual este sistema se transforma en un modo de producción nuevo y radicalmente revolucionario" (Dos Santos, 1998). 8 La referencia bibliográfica de la p. 47 de PO (2010) reenvía a la edición francesa, Études et Documentation Internationales, París, 1965, p. 62. Para la elaboración del presente trabajo se accedió a la segunda edición en castellano publicada por Ediciones ryr La Rosa Rebelde, Buenos Aires, 2007.
} 
proletariado" (Lukács, 2007: 56). En este punto, la importancia que Lenin otorga a la organización es señalada por Lukács como una ruptura con el "fatalismo mecanicista":

(...) el que concibe a la conciencia de clase del proletariado como un producto mecánico de su situación de clase y el que no ve en la revolución misma más que el efecto mecánico de fuerzas económicas que se desencadenan por fatalidad (Lukács, 2007: 60)

(...) Sería aplicar mecánicamente la teoría marxista (...) si se llegara a imaginar que la conciencia de clase verdadera y capaz de conducir a la toma del poder es capaz de nacer espontáneamente en el seno del proletariado, progresivamente, sin tropiezos, sin regresiones, como si el proletariado pudiera adquirir ideológicamente su vocación revolucionaria de acuerdo a una línea de clase. (Lukács, 2007: 53)

Desde esta óptica, la relevancia del partido dirigente del proletariado se justifica ampliamente partiendo de reconocer el impacto de la alienación en la conciencia proletaria y su consecuente sujeción intelectual a la lógica encubridora que impregna la sociedad burguesa. La "adherencia” al opresor y la “inmersión” de la conciencia, en Freire.

Y, si bien no es el accionar del partido el que produce el proceso revolucionario, le cabe a este la función de anticipar la evolución de la estructura económica y, desde allí, establecer la estrategia de la acción proletaria en cada coyuntura de ese desarrollo y formar a la clase proletaria para "la defensa de sus intereses en función de este porvenir, en el plano intelectual, material y organizativo" (Lukács, 2007: 61). En la visión de Lukács, estas tareas requieren que el sector dirigente del partido comunista reúna dos condiciones: un alto nivel de entrega a la causa revolucionaria e, igualmente relevante, una adecuada articulación con la clase proletaria. La atención que presta Lukács a este último aspecto lo lleva a afirmar que corresponde al liderazgo revolucionario, "siendo receptivo y adaptable, sacar provecho de todas las manifestaciones provenientes de las masas, por confusas que sean y revelar a las masas las posibilidades revolucionarias que ellas son incapaces de ver por sí mismas” (Lukács, 2007: 64).

Lukács postula que la conciencia de clase se adquiere, en el terreno práctico, en el curso de la lucha como proceso en permanente transformación, en correspondencia con los cambios de sus bases sociales y materiales. En este proceso, el partido adquiere el carácter de una vanguardia que vela por la claridad teórica y el ajuste de la práctica revolucionaria a los intereses proletarios, situándose en la lucha de clases no más que "un paso" delante de las masas.

En este punto, Lewis (2007) aporta una interesante reflexión en torno a las articulaciones posibles de establecer entre estos desarrollos de Lukács y las ideas de Freire. En referencia a sus respectivas concepciones de organización y dirigencia revolucionarias, postula la idea de que el pedagogo brasileño estaría respondiendo a una pregunta que abre Lukács: el interrogante que apuntaría a delimitar qué pedagogía permitiría plantear tales relaciones entre los dirigentes revolucionarios y las masas. Una cuestión que Lewis advierte como ausente en la teoría de la vanguardia.

Al respecto, Freire coincide con Lukács en que la actitud "contemplativa" de los oprimidos frente a la explotación, que genera el fenómeno de la cosificación en el mundo burgués, no permite suponer que la conciencia de clase "atribuida" se producirá mecánicamente. Sin embargo, plantea aquí una relativa diferencia con el pensamiento lukácsiano. Para el pedagogo

(...) el problema no radica en "explicar a las masas”, sino en dialogar con ellas sobre su acción. De cualquier forma, el deber que Lukács reconoce al partido revolucionario de "explicar a las masas su acción" coincide con la exigencia que planteamos sobre 
la inserción crítica de las masas en su realidad, a través de la praxis, por el hecho de que ninguna realidad se transforma a sí misma. (Freire, 2010: 48)

Esta insistencia en el valor ético y estratégico del diálogo se inscribe en la discusión de Freire con la pedagogía "bancaria" dominante. Desde su perspectiva, esta impregna las prácticas del sistema educativo, pero también las de los partidos de izquierda con los cuales él se vincula en las décadas de 1950 y 1960, en sus trabajos educativos en el nordeste de su país. Es visible, a lo largo de la obra del pedagogo brasileño, su rechazo sostenido de lo que él considera un sectarismo de izquierda y sus prevenciones sobre las implicancias éticas y prácticas del ejercicio de un liderazgo revolucionario basado en la "antidialogicidad" como matriz de acción cultural. En efecto, respecto de la posición en que se coloca a los oprimidos en esta matriz, señala que

(...) aunque los contenidos de este diálogo necesariamente se irán modificando, sustituirlos por el antidiálogo, por la esloganización, por la verticalidad, por los comunicados, (...) es transformarlos en objetos. (Freire, 2010: 63)

No existe otro camino sino el de la práctica de una pedagogía liberadora, en que el liderazgo revolucionario, en vez de sobreponerse a los oprimidos y mantenerlos en el estado de "cosas", establece con ellos una relación permanentemente dialógica. (Freire, 2010: 67)

Por, último, y en torno a esta cuestión, cabe destacar que la adhesión al pensamiento de Lukács se complementa con la referencia a la perspectiva de Mao, a la que Freire alude en PO: la noción de que corresponde a los dirigentes "enseñar a las masas con precisión lo que hemos recibido de ellas con confusión” (Freire, 2010: 105, citando a Malraux, 1965: 531).

\section{A modo de cierre}

Resulta relevante, tanto para el pensamiento pedagógico presente como para las prácticas latinoamericanas referenciadas en la Educación Popular de inspiración freireana, profundizar la crítica de las nociones que este autor desarrolla en sus obras, con foco en la articulación de las experiencias culturales de los sectores populares con la política, la pedagogía y el poder (Giroux, 2016). Se trata de desarmar el aparente carácter circular del pensamiento del educador brasileño y abordar su consistencia interna, delimitando aquellas afirmaciones que adquieren el carácter de categorías analíticas para dar cuenta de los procesos de dominación social. En esta tarea, la contrastación de su pensamiento con el análisis materialista histórico, en sus variantes, constituye una prioridad.

Al respecto de las relaciones que es posible establecer entre Freire y Lukács, las ideas de la no determinación de la conciencia por la estructura material, la posibilidad de que la conciencia proletaria rompa el cerco de la cosificación e invierta la lógica hegemónica de la burguesía para luchar por la transformación de las estructuras de dominación, así como el lugar que ocupan la acción, la práctica, la organización y el liderazgo revolucionario en este proceso, se presentan en este primer análisis como nociones en las que se registran capilaridades entre ambos autores, más allá de los contextos históricos y geográficos y de las tradiciones intelectuales en que se inscriben. 


\section{Dibliografía}

"Bavasso, C. (2008). El pensamiento de Georg Lukács. Papeles de trabajo. Revista electrónica del Instituto de Altos Estudios Sociales de la Universidad Nacional de General San Martín, año 2, nº 4, Buenos Aires.

»Coben, D. (2001). Gramsci y Freire, héroes radicales. Políticas en Educación de Adultos. Madrid, Miño y Dávila/Fundación Paideia.

"Freire, P. (2009 [1994]). Pedagogía de la esperanza. Un reencuentro con la pedagogía del oprimido. Buenos Aires, Siglo XXI.

》Freire, P. (2010 [1973]). Pedagogía del Oprimido, $3^{\underline{a}}$ ed. Buenos Aires, Siglo XXI.

" Gerhardt, H.-P. (1993). "Paulo Freire" (1921-1997). Perspectivas: revista trimestral de educación comparada, vol. XXIII, nº 3-4, 463-484. París, Unesco-Oficina Internacional de Educación.

" Giroux, H. (2016). Critical Pedagogy, Paulo Freire and the courage to be political. Revista e-Curriculum, São Paulo, vol. 14, nº 01: 296-306 jan./mar., Programa de Pósgraduação Educação: Currículo-PUC/SP. Disponible en: http://revistas.pucsp.br/ index.php/curriculum

"Lewis, T. E. (2007). Revolutionary Leadership Revolutionary Pedagogy: Reevaluating the Links and Disjunctions Between Lukács and Freire. En Philosophy of Education, pp. 285.-293. Nueva Jersey, Montclair State University.

» Lukács, G. (1984). Historia y conciencia de clase. Madrid, Sarpe Tomos I y II.

"Lukács, G. (2007). Cap. III. En Lenin. $2^{\mathrm{a}}$ ed. en castellano. Buenos Aires, Ediciones ryr-La Rosa Blindada.

» Mayo, P. (2010 [1970]). Comentario de textos clásicos. Paulo Freire, Pedagogía del oprimido. Montevideo: Tierra Nueva. Textos clásicos, no 13. Indicadores para una pedagogía con conciencia política. Oxford University Press and Community Development Journal.

"Paiva, V. (1982). Populismo católico y educación, una experiencia brasileña. Cuadernos Políticos, nํ34; 22-39. México D.F., Era.

》Puiggrós, A. (1986). Democracia y autoritarismo en la pedagogía argentina y latinoamericana, Cap. 1. Buenos Aires. Galerna.

"Rodríguez, L. M. (2008) Apuntes sobre el pensamiento político pedagógico de Paulo Freire. Tesis doctoral en Filosofía por la Universidad de París VIII (mimeo).

"Santos, T. dos. (1998). La teoría de la dependencia un balance histórico y teórico. En López Segrera, F. (ed.). Los retos de la globalización. Ensayo en homenaje a Theotonio Dos Santos. Caracas, Unesco. Disponible en: http://bibliotecavirtual.clacso.org.ar/ ar/libros/unesco/santos.rtf

» Scocuglia, A. C. (1999). A construção da história das idéias de Paulo Freire. En Streck, D. (org.). Paulo Freire: ética, utopia e educação, pp. 29-51. Petrópolis, Vozes.

»Scocuglia, A. C. (2001). A progressão do pensamento político-pedagógico de Paulo Freire. En Torres, C. A. (comp.). Paulo Freire y la agenda de la educación latinoamericana en el siglo XXI, pp. 323-348. Buenos Aires, CLACSO.

» Torres, R. M. (2001). Los múltiples Paulo Freire. En Araujo Freire, A. M. (comp.). A pedagogia da libertacao em Paulo Freire. Sao Paulo, UNESP. 


\section{Florencia M. Finnegan}

Licenciada en Ciencias de la Educación, Universidad de Buenos Aires. Diploma de Estudios Avanzados en Política y Economía-IDAES. Docente e investigadora Universidad Pedagógica Nacional, Universidad Nacional de San Martín. florfine@ gmail.com 